\title{
The Effect of Learner Variables on Phraseological Proficiency
}

\author{
Kathrin Kircili \\ Justus Liebig University, Giessen, Germany \\ Kathrin.Kircilieanglistik.uni-giessen.de
}

\begin{abstract}
This paper is based on an empirical study which investigated the effects of learner variables on phraseological proficiency, a topic which has so far not received a lot of attention in phraseological research. By means of a questionnaire enquiring a variety of personal details as well as testing the participants' theoretical as well as their productive and receptive knowledge with regard to phraseology in general and collocations and phrasal verbs in particular, it was found that both longer periods abroad and a regular exposure to the English language have a very positive effect on a learner's practical abilities in this field, although, in direct comparison, the former is still the most effective way to improve a learner's phraseological proficiency - particularly when it comes to phraseological units that are highly idiomatic or easily confusable with a learner's native language.
\end{abstract}

Keywords: phraseology, EFL, language proficiency

\section{Theoretical Background}

When acquiring a foreign language, it is the ultimate aim of most students to develop a native-like knowledge of the respective L2. This encompasses proficiency not only with regard to grammar but also concerning vocabulary, since a rich vocabulary knowledge is the most important basis to enable communication. However, the mere acquisition of individual words does often not suffice, firstly, because the context in which a word is used has an influence on its meaning, and secondly, because "much of communication makes use of fixed expressions memorized as formulaic chunks" [2]. These so-called phraseological units, which comprise more than 55 percent of spoken and written English [3], often give away non-native speakers and pose a major difficulty - even for advanced learners of English. So far phraseological research in learner languages has mainly concentrated on the connection between a learner's L1 and his or her use of phraseological phenomena such as phrasal verbs or collocations in the English language. As far as the former are concerned, it has been revealed that it is particularly learners whose L1 does not contain phrasal verbs who either refrain from using them and prefer one-word synonyms instead [1] or show a higher frequency of erroneous uses than those learners in whose L1 the phenomenon is actually existent in a similar fashion [9]. With regard to collocations, learners are particularly likely to be influenced by their L1, which has, in previous research, been observed in 
up to 53\% of the occurrences [7]. This either results in word-for-word translations from the $\mathrm{L} 1$ into the $\mathrm{L} 2$ or in an attempt to adapt a word combination to the $\mathrm{L} 2$ to a certain extent $[7 ; 8]$. The effect of learning context variables on phraseological proficiency, however, is a topic that has mainly been neglected so far [5]. Although, in second language acquisition, it is a known fact that learner variables have an influence on a learner's overall performance, they "suddenly become a homogeneous group" [10] when it comes to the investigation of their phraseological proficiency. The empirical study this paper is based on broke with this habit and aimed at the investigation of learner variables and their effects on a student's proficiency in a linguistic field that is particularly advantageous for learners of English because it increases their overall fluency [5] due to a decrease in processing efforts [4; 7] and a more efficient retrieval of word combinations [6]. Consequently, the aim of this study was to find out which personal factors actually influence the productive and receptive knowledge of certain phraseological phenomena.

\section{Database}

The questionnaire used was comprised of three parts. The first section served to obtain personal information, enquiring the participants' age, gender, field of studies, experience abroad as well as the frequency of exposure to and use of the English language outside the university context. In the second part, the theoretical knowledge of phraseology was tested by asking for definitions and examples of the phenomena relevant for the study. The final part consisted of 40 sentences in which the productive and receptive knowledge of verb/noun as well as adjective/noun collocations and phrasal verbs was tested, all of which were made up of high-frequency adjectives or verbs such as DO, HAVE or MAKE. In the production tasks, participants were asked to fill in the blanks while in the reception task it had to be decided whether the underlined part in a given sentence was correct or incorrect. Examples included:

\section{Verb/noun collocations}

a. Production: It won't ___ you any harm if you help her. (do)

b. Reception: She got a baby when she was sixteen years old. (incorrect)

2. Adjective/noun collocations

a. Production: She knows a lot about animals and the environment, but she only has knowledge of computers. (little)

b. Reception: He is a strong smoker. He smokes at least 25 cigarettes a day.

(incorrect)

\section{Phrasal verbs}

a. Production: Most people would love to do (away) with Mondays.

b. Reception: Little Jason was very proud when his teeth finally fell out. (correct) 
A total number of $161 \mathrm{EFL}$ learners participated in the survey. Some of the results yielded will be presented in the following.

\section{$3 \quad$ Findings}

Fig. 1. illustrates the performances of students who had spent a period of more than six months in an English-speaking country compared to those without any experience abroad.

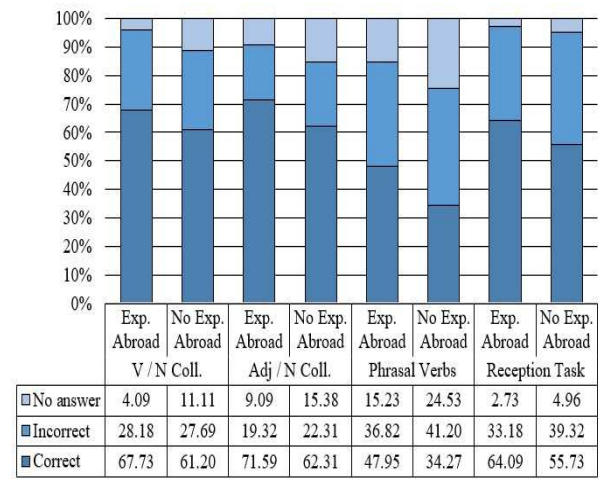

Fig. 1. Results of 44 students with and 117 without experience abroad

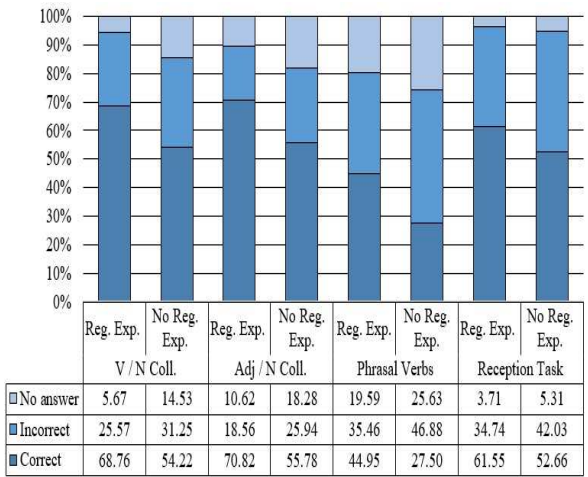

Fig. 2. Results of 97 students with and 64 students without regular exposure to L2

In fact, the differences in each of the four question groups were highly significant $(\mathrm{p}<0.001),{ }^{1}$ with the most striking result having been determined in the phrasal verb exercises. This is particularly interesting since this kind of PU is mostly used in informal contexts and is therefore more frequent in speech than in writing. Hence, the results prove that longer periods abroad, during which EFL learners have the opportunity to talk to native speakers on a daily basis, make a considerable difference in an area that is otherwise so troublesome for learners of English. Likewise, students with experience abroad were much less likely to fall prey to false friends such as sleep in or to confuse common German collocations with English ones (e.g. black vs. blue eye; have vs. get a baby). As Fig. 2 above illustrates, similarly clear results could be determined for students who indicated a regular exposure to the English language outside university by reading and writing English texts, watching TV or talking to native speakers on a regular basis. In total, 97 participants met the stipulated requirements of at least two activities being performed daily or weekly. Again, the differences between the two groups of participants were highly significant in all of the four question groups (for all $\mathrm{p}<0.001$ ). Although it seems natural for an EFL learner to improve his or her language skills when regularly in contact with a language, it is particularly interesting here that the p-values actually indicate that, even though all of them are highly significant, the measured differences between these two groups of participants were even bigger than those determined between students with and those without experience abroad. This holds particularly true for the tasks on V/N

\footnotetext{
${ }^{1}$ The $\mathrm{p}$-values were determined by means of a t-test.
} 
collocations as well as the phrasal verb exercises. Now, due to the clear results of the first two comparisons, the final analysis sought to establish a connection between them by taking a look at the students who had not been abroad but indicated a regular exposure to the L2 and comparing them with those who had been in an Englishspeaking country for a longer period of time.

As Fig. 3 indicates, it was found that a regular exposure can result in a comparable proficiency, at least as far as the collocation tasks were concerned in case of which there was no longer a significant difference with p-values above the significance threshold of 0.05 for both $\mathrm{V} / \mathrm{N}$ and $\mathrm{A} / \mathrm{N}$ collocations.

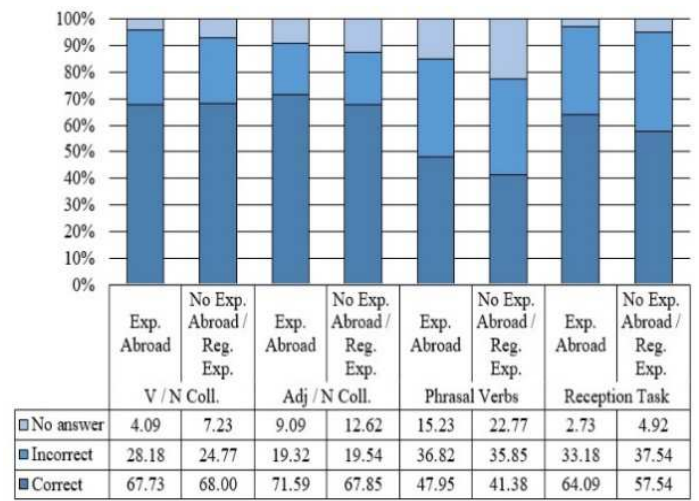

Fig. 3. Results of 44 students with experience abroad and 65 students without but with a regular exposure to the L2

With regard to phrasal verbs and the reception tasks, however, the results were again significant $(\mathrm{p}<0.001$ and $\mathrm{p}<0.05$, respectively) particularly with regard to idiomatic PUs as well as false friends, such as take after, sleep in or get a baby.

\section{Conclusion and Outlook}

This survey revealed that a longer period spent in an English-speaking country is indeed the most effective way to improve one's phraseological proficiency. However, even though the acquisition of a language in its native environment is inevitable if students aim for a native-like proficiency and wish to master even highly idiomatic structures and reduce the influence of their L1, a regular spare time exposure to the language also proved to be a valid way to enhance one's phraseological competence. Moreover, the results also showed that the generally high frequency of a certain verb does not necessarily imply that their various functions in a collocation or phrasal verb are equally known to EFL learners. It becomes clear that the acquisition of the phenomena is strongly connected to language contact although their complexity would justify an emphasis in school curricula as well. Since this paper only focused on small number of factors that influence advanced learners' phraseological proficiency, future analyses that focus on effects of other learning context variables such as age, gender or the field of studies might also yield interesting results. Additionally, a comparable study focusing on students' phraseological abilities in speech would help to uncover 
register differences in learners' phraseological proficiency. Since the questionnaire did not have a time limit and the participants were free to take as much time as they needed, it does not necessarily shed light on the EFL learners' spontaneous reaction. Spontaneity and the ability to use language in speech, however, tells a lot about a speaker's true proficiency and should therefore be included in further investigations.

\section{References}

[1] Dagut, M., Laufer B.: Avoidance of phrasal verbs: A case for contrastive analysis. Studies in Second Language Acquisition 7(1), 73-79 (1985).

[2] Ellis, N.: Phraseology: The periphery and the heart of language. In: Meunier, F., Granger, S. (eds.) Phraseology in Foreign Language Learning and Teaching, pp. 113. John Benjamins, Amsterdam / Philadelphia (2008).

[3] Erman, B. Warren B.: The idiom principle and the open choice principle. Text and Talk - An Interdisciplinary Journal of Language, Discourse \& Communication Studies, 20(1), 29-62 (2000).

[4] Fiedler, S.: English Phraseology: A Coursebook. Narr Francke Attempto Verlag $\mathrm{GmbH}$, Tübingen (2007).

[5] Granger, S.: From phraseology to pedagogy: challenges and prospects. In: Herbst, T., Faulhaber, S., Uhrig, P. (eds.) The Phraseological View of Language: A Tribute to John Sinclair, pp. 123-146. Walter de Gruyter GmbH, Berlin (2011).

[6] Nattinger, J., DeCarrico J.: Lexical Phrases and Language Teaching. $2^{\text {nd }}$ edn. Oxford University Press, Oxford (2001).

[7] Nesselhauf, N.: Collocations in a Learner Corpus. John Benjamins, Amsterdam / Philadelphia (2005).

[8] Paquot, M.: Exemplification in learner writing: A cross - linguistic perspective. In: Meunier, F., Granger, S. (eds.) Phraseology in Foreign Language Learning and Teaching, 101-119. John Benjamins, Amsterdam / Philadelphia (2008).

[9] Sjöholm, K. The Influence of Cosslinguistic, Semantic, and Input Factors on the Acquisition of English Phrasal Verbs: A Comparison between Finnish and Swedish Learners at an Intermediate and Advanced Level. Åbo Akademi University Press, Åbo (1995).

[10] Wray, A.: Formulaic Language and the Lexicon. Cambridge University Press, Cambridge: Cambridge (2002). 